\title{
Role of dietary concentrates on the venison quality of Sika deer (Cervus nippon)
}

\author{
K.W. Kim", M.M.R. Chowdhury, ${ }^{1,2}$, D. Jeon ${ }^{1}$, J. Lee ${ }^{1}$, S.S. Lee ${ }^{1}$, D.H. Kim ${ }^{3}$, S.W. Kim ${ }^{4}$ \\ \& S.H. Lee ${ }^{1, \#}$ \\ ${ }^{1}$ Animal Genetic Resources Research Center, National Institute of Animal Science, Rural Development Administration, \\ Republic of Korea \\ ${ }^{2}$ Department of Physiology and Pharmacology, Faculty of Animal Science and Veterinary Medicine, Patuakhali Science \\ and Technology University, Bangladesh \\ ${ }^{3}$ Department of Animal Science, GyeongBuk Provincial College, Republic of Korea \\ ${ }^{4}$ International Agricultural Development and Cooperation Center, Chonbuk National University, Republic of Korea
}

(Received 24 May 2019; Accepted 15 August 2019; First published online 4 September 2019)

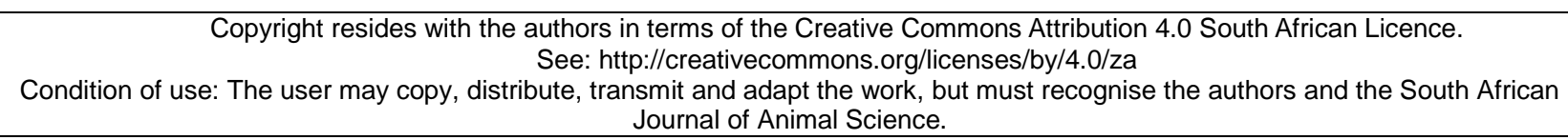

\begin{abstract}
The aim of this study was to evaluate the effect of feed concentrate level on carcass characteristics and meat quality of sika deer (Cervus nippon). A total of 16 sika deer (mean bodyweight $30 \mathrm{~kg}$ ) were randomly assigned to one of two treatments, namely Treatment 1 (T1): fed concentrate at $1.5 \%$ of total bodyweight); and Treatment 2 (T2): fed concentrate ad libitum. Both groups had free access to roughage (hay) and water. Each group was fed concentrate twice daily (at 09h00 and 16h00) for eight months. The fat concentration of venison from deer in T2 was significantly greater than that of T1. However, fat loss through cooking, shear force, and $\mathrm{pH}$ did not differ significantly between the two groups. Water-binding capacity of venison from deer in T1 was significantly greater (2.83\%) than that of T2. Colour parameters $\mathrm{a}^{*}$ (redness) and $b^{\star}$ (yellowness) were significantly greater for venison from T2 than for deer in T1. Likewise, cholesterol concentration of venison from deer in T2 was significantly greater than for deer in T1. However, the cholesterol concentration in venison from deer that were subjected to both treatments was less than that of meat from other livestock species. In conclusion, the results of this study provide a baseline to estimate fodder cost standards to produce sika deer venison, and would aid commercial deer farmers in developing optimal management strategies for venison production.
\end{abstract}

Keywords: carcass composition, concentrate feeding, meat quality

"Co-corresponding author: deerking@jbnu.ac.kr; sanghoon@korea.kr

\section{Introduction}

Deer grow seasonally, and thus can gain weight rapidly during spring and summer and lose most of their fat in autumn and winter (Drew, 1985). Venison is a valuable meat product, which contains more protein and lower fat and cholesterol concentrations than traditional red meats (Drew et al., 1991; Shin et al., 2000). Moreover, deer venison fulfils most of the nutritional requirements of consumers owing to its low fat and cholesterol concentrations, very high carbohydrate concentration, and high concentration of proteins, minerals, and trace elements (Hoffman \& Wiklund, 2006). Most deer species also have low concentrations of structural lipids (phospholipids and cholesterol) and triglycerides in their muscles, and possess a desirable fatty acid profile (Volpelli et al., 2003). Advanced livestock-producing countries such as New Zealand have developed a pasture-based system for venison production, which accounts for more than $80 \%$ of the deer breeding industry. Venison from elk and red deer have been studied for their physicochemical characteristics (Zomborszky et al., 1996), their quality, based on slaughter methods (Wiklund et al., 2001), optimal packaging conditions (Vergara et al., 2003), and fatty acid composition based on feed characteristics (Volpelli et al., 2003).

Important indices of meat quality include $\mathrm{pH}$ and meat colour. The $\mathrm{pH}$ of high-quality meat ranges from 5.4 to 5.6 . At a pH greater than 5.8 , meat delicacy decreases, and there is a risk of reducing meat quality 
with ageing (Goñi et al., 2007). The same quality parameters are considered for evaluating meat and carcasses intended for export (Page et al., 2001; Goñi et al., 2007). Customers believe that the commercial meat products should possess adequate nutritional value, juiciness, flavour, and tenderness, as well as being wholesome, fresh, and lean (Dransfield, 2003; Ngapo \& Dransfield, 2006).

In Korea, deer are bred for their antlers and pasture-based venison production is almost non-existent. Moreover, deer farming has been decreasing steadily in Korea since 2001 (Ministry of Agriculture Food and Rural Affairs, 2015). Furthermore, there has been a lack of research on developing systematic and efficient deer breeding strategies with a superior management approach (Kim et al., 2017). Few studies have been conducted on sika deer owing to their sensitive nature and there have been almost no studies on the effect of feed concentrate level on venison production and meat quality. Moreover, efficient feeding, care, and management practices for sika deer have not been studied. Farmed deer are frequently fed concentrates over the winter, the need for which results from deficiencies in the quality of pastoral feed (Flesch et al., 2002; Tuckwell, 2003). Thus, little is known about the relationship between concentrate supplementation and meat production in farmed deer. Therefore, the present study was aimed at investigating the effects of concentrate supplementation on the physicochemical qualities of venison.

\section{Materials and Methods}

All animals were raised at the Animal Genetic Resources Centre, National Institute of Animal Science (NIAS), Namwon, Korea. All experimental procedures were performed in accordance with the guidelines of the Animal Care and Use Committee of NIAS with its approval, as required by its regulations for animal welfare.

At the commencement of the trial, the mean age and weight of the sika deer $(n=16)$ was estimated to be four to six years and $30 \mathrm{~kg}$, respectively. During the experiment the deer were kept in a large confined area for eight months. They had ad libitum access to treated hay grass (without fresh grass), fresh water and air. The hay was the major roughage source for deer during the experimental period. The deer were randomly assigned to one of two treatment groups in which they were fed concentrate feeds at $1.5 \%$ of total bodyweight (T1) or ad libitum (T2) twice a day (09:00 and 16:00). The authors. investigated the effects of these treatments on carcass characteristics, meat colour, and meat quality by determining cooking loss, shear force, water holding capacity $(\mathrm{WHC}), \mathrm{pH}$, and cholesterol concentration of the sika deer. The ingredients and chemical composition of the concentrate feed were analysed using a slightly modified method of the Association of Official Analytical Chemists (AOAC, 1995). The resulting chemical composition is shown in Table 1.

Table 1 Chemical composition (\% of dry matter) of the concentrate provided as a supplement to treated hay fed to sika deer

\begin{tabular}{lcc}
\hline Chemical composition & Concentrate feed & Treated hay \\
\hline & & 25.1 \\
Dry matter & 88.9 & 18.1 \\
Crude protein & 18.9 & 5.52 \\
Ether extract & 2.26 & 8.46 \\
Crude ash & 6.85 & 30.3 \\
Crude fibre & 7.71 & 61.3 \\
Neutral detergent fibre & 23.61 & 32.0 \\
Acid detergent fibre & 10.31 & \\
\hline
\end{tabular}

The experimental animals were slaughtered at the NIAS slaughterhouse using their standard procedures. Three deer from each treatment group whose gross weight was similar were slaughtered. The carcass yield was determined using an electronic balance (Table 2). Carcass weight refers to the weight after removal of the head, legs, viscera, and ankles. Live weight, carcass weight, fat content, and bone content were calculated as percentages.

Meat colour was determined in the fresh longissimus muscle (cross-section of the Longissimus thoracis) 48 hours after slaughter using Minolta chroma meter CR-310 (Minolta Co., Ltd., Osaka, Japan), with a colour measuring area of $50 \mathrm{~mm}$ in diameter, in a CIE- $L^{*} a^{*} b^{\star}$ colour system, where $L^{*}$ value 
designates lightness, ranging from 0 (for black) to 100 (for ideal white), and $a^{\star}$ and $b^{\star}$ are colour coordinates $\left(+a^{*}=\right.$ redness, $-a^{*}=$ green, $+b^{\star}=$ yellow, and $-b^{*}=$ blue $)$. Consistent with the manufacturer's protocol, a standard colour plate with $L^{*}=94.5, a^{*}=0.3136$, and $b^{\star}=0.3203$ was used for calibration and the mean of three measurements was used to represent each animal. The colour intensity/saturation $\left(C^{\star}\right)$ and $h^{\star}$ indices were calculated as follows:

$$
\begin{gathered}
C^{*}=\sqrt{\left(a^{*}\right)^{2}+\left(b^{*}\right)^{2}} \\
h^{*}=\arctan \left(\frac{b^{*}}{a^{*}}\right)
\end{gathered}
$$

where: $C^{*}$ represents the colour and $h^{*}$ represents its type.

Shear force $\left(\mathrm{kg} / 0.5 \mathrm{inch}^{2}\right)$ was measured according to the method of Wheeler et al. (2000). Briefly, the meat sample was cut into steaks ( $3 \mathrm{~cm}$ in thickness) perpendicular to the muscle fibre orientation, heated to $70{ }^{\circ} \mathrm{C}$, and cooled in running water for $10 \mathrm{~min}$. The meat core sample was collected by drilling a cylindrical core of $1.27 \mathrm{~cm}$ diameter along the direction of the muscle fibre. The Warner-Bratzler shear meter (G-R Electrical Manufacturing Co., Manhattan, Kansas, USA) was used for all measurements.

To measure the cooking loss of the samples, the raw venison was cored into 25-g portions, enclosed in a polyvinyl iodine chloride film, and heated for $30 \mathrm{~min}$ until the core temperature reached $70^{\circ} \mathrm{C}$. Water loss was measured by calculating the weight difference before and after cooking, and expressed as percentage. Moisture loss was measured after a cooling period of 1 hour at optimal temperature, which was then used in the following equation to calculate cooking loss:

$$
\text { Cooking loss }(\%)=\frac{\text { Moisture loss }(\mathrm{g})}{\text { Sample weight }(\mathrm{g})} \times 100
$$

Ten grams of the sample were homogenized with $90 \mathrm{~mL}$ distilled water at 13,500 rpm for 20 seconds using a homogenizer (T25B, IKA-Works Asia, Kuala Lumpur, Malaysia). A pH meter (8603, Metrohm AG, Herisau, Switzerland) was used to measure the $\mathrm{pH}$ three times with the mean $\mathrm{pH}$ being recorded for each animal.

Water-holding capacity (WHC) was measured using a centrifugation method (Ryoichi et al., 1993). Briefly, a 300-mg muscle sample was placed in a filter-press device and compressed for 2 min. WHC was calculated from duplicate samples as a ratio of the meat film area to the total area. Hence, a large meat film value would result in high WHC. WHC (\%) was calculated as follows:

$$
\text { WHC }(\%)=100-\left(\frac{\text { Total meat area }}{\text { Meat film area }} \times 100\right)
$$

Cholesterol concentration was determined using a modified procedure of King et al. (1998). Briefly, 10 $\mathrm{mL}$ saponification reagent $(33 \% \mathrm{KOH} /$ ethanol $(\mathrm{w} / \mathrm{v}), 6: 94)$ was added to the lipid extract. Then, the sample was homogenized and incubated at $50{ }^{\circ} \mathrm{C}$ for 1 hour. After cooling, $5 \mathrm{~mL}$ distilled water and $5 \mathrm{~mL}$ hexane were added. The contents were mixed thoroughly and the hexane layer, which contained unsaponifiable matter, was dried using nitrogen gas (99.99\%). The dried sample was then mixed with $200 \mu \mathrm{L}$ pyridine and $100 \mu \mathrm{L}$ Sylon bis (trimethylsilyl) trifluoroacetamide (99\% bistrifluoroacetamide $+1 \%$ trimethylchlorosilane and derivatives) and incubated at $50{ }^{\circ} \mathrm{C}$ for 1 hour. Analysis was performed using a gas chromatograph (HP 6890, Rolla Biotech, Anaheim, CA, USA) equipped with an on-column capillary injector and a flame ionization detector. A capillary column (HP5, $30 \mathrm{~m} \times 0.25 \mathrm{~mm} \times 0.25 \mu \mathrm{m})$ and a ramped oven temperature were used (increased from $180^{\circ} \mathrm{C}$ at $8{ }^{\circ} \mathrm{C} / \mathrm{min}$ to $260^{\circ} \mathrm{C}$, then to $280^{\circ} \mathrm{C}$ at $2{ }^{\circ} \mathrm{C} / \mathrm{min}$ ). The amounts of cholesterol were calculated using $5 \alpha$-cholestane as an internal standard.

Data were analysed using SAS version 9.4 (SAS Institute, Cary, NC, USA). Treatment effects were determined by one-way analysis of variance (ANOVA). In all cases, a $P$ value less than 0.05 was considered significant.

\section{Results and Discussion}

Carcass composition is important for meat producers, abattoirs, and distributors to determine the economic value of an animal, as each cut has a specific commercial value (Kudrnáčová et al., 2018). Table 2 shows the carcass yield of sika deer fed the various levels of supplemental concentrate. The carcass characteristics did not differ $(P>0.05)$ between the treatment groups. Live weight at slaughter of the T1 group was greater than that in the T2 group and the fat weight from carcasses of deer in the T2 group was greater than that for deer in the T1 group. 
Serrano et al. (2019) observed carcass yields for deer between 55\% and 60\%, although this value would differ according to the genetic composition, sex, diet, fasting time prior to slaughter, type of slaughter (hunting method and projectile location), and carcass weight. Furthermore, the carcass weight depends on the species, slaughter age, and sex of animals (Serrano et al., 2019). It is commonly believed that providing concentrate feeds during the later stages of fattening may reduce the slaughter weight because of decreased feed intake owing to the manifestation of metabolic diseases. However, the current study, along with others on black goats (Choi et al., 2007), sheep (Mazumder et al., 1998), and deer (Webster et al., 2000), revealed increases in animal growth resulting from increased dietary energy levels.

Table 2 Treatment means for live weight and carcass traits for venison from sika deer fed supplemental concentrate at $1.5 \%$ of live weight (T1) or ad libitum (T2) ${ }^{\mathrm{a}}$

\begin{tabular}{lcc}
\hline \multirow{2}{*}{ Trait } & \multicolumn{2}{c}{ Treatment } \\
\cline { 2 - 3 } & T1 & T2 \\
\hline Live weight (kg) & $36.0 \pm 1.5$ & $43.0 \pm 2.8$ \\
Carcass weight (kg) & $17.7 \pm 1.15$ & $24.6 \pm 1.9$ \\
Carcass (\%) & $49.2 \pm 2.06$ & $57.1 \pm 2.10$ \\
Retail cut weight (kg) & $13.5 \pm 0.28$ & $17.3 \pm 1.79$ \\
Retail cut (\%) & $76.0 \pm 1.16$ & $70.7 \pm 1.55$ \\
Bone (kg) & $3.40 \pm 0.23$ & $3.9 \pm 0.05$ \\
Fat (kg) & $2.40 \pm 0.52$ & $3.1 \pm 0.51$ \\
\hline
\end{tabular}

${ }^{\mathrm{a}} \mathrm{N}=8$ for live total weight of each group and $\mathrm{N}=3$ for carcass traits of each treatment

Meat colour is an important indicator of meat quality and may vary depending on livestock variety, animal sex, muscle myoglobin level, and livestock feed (Cornforth, 1994). Table 3 shows the changes in meat colour of sirloin that resulted from differences in concentrate feed supplementation. The $L^{*}$ value (lightness) did not differ between T1 and T2 $(P<0.05)$. However, $\mathrm{a}^{\star}$ value (redness) and $\mathrm{b}^{*}$ value (yellowness) increased with an enhanced intake of concentrate feeds $(P>0.05)$. Kadim et al. (2004) reported Omani beef harvested in the hot season had significantly darker meat than beef from animals that were slaughtered in the cold season with $L^{*} 31.45$ versus 35.58 , $a^{*} 18.53$ versus 23.19 , and $b^{*} 4.16$ versus 6.40 colour measurements. Cho et al. (2011) observed $L^{*}$ values in the range of 41.33 to 40.80 for the Korean beef sirloin. $L^{*}$ values for horse meat may range from 36.8 to 37.10 (Chae et al., 2013). The venison in this study had $L^{*}$ values that were lower than those of Korean beef and were more similar to the $L^{*}$ values exhibited by horse meat and Omani beef cattle. According to Piaskowska et al. (2015), the hind and stag (Dama dama L.) have different meat colours. The significant differences in colour that was observed between treatments may be because of the more subtle differences in the fat percentage.

Table 3 Treatment means for the colour of venison from sika deer fed supplemental concentrate at $1.5 \%$ of live weight (T1) or ad libitum (T2)

\begin{tabular}{|c|c|c|}
\hline \multirow{2}{*}{ Parameter } & \multicolumn{2}{|c|}{ Treatment $^{*}$} \\
\hline & $\mathrm{T} 1(\mathrm{n}=3)$ & T2 $(n=3)$ \\
\hline CIE L* (lightness) & $34.4 \pm 2.20$ & $34.6 \pm 2.42$ \\
\hline CIE $a^{\star}$ (redness) & $15.1 \pm 0.51^{b}$ & $16.7 \pm 1.42^{\mathrm{a}}$ \\
\hline CIE b* (yellowness) & $4.2 \pm 0.41^{\mathrm{a}}$ & $5.8 \pm 0.98^{b}$ \\
\hline
\end{tabular}


Table 4 shows the differences in cooking loss, shear force, $\mathrm{pH}$, and WHC between the treated groups following supplementation of dietary concentrate to sika deer. The cooking loss percentage, which indicates the ratio of weight lost after heating, did not differ between the groups $(P>0.05)$. Shear force was $8.09 \mathrm{~kg}$ for T1 and $7.85 \mathrm{~kg}$ for T2. Thus, shear force tended to decrease as the concentrate feed level increased. However, the difference was not significant $(P>0.05)$. Changes in $\mathrm{pH}$ affect meat quality, similar to cooking loss, WHC, and softness. In these data, $\mathrm{pH}$ did not differ between T1 and T2 $(P<0.05)$. The dark colour of deer meat is owing to its high $\mathrm{pH}$, which is caused by a high rate of ante-mortem glycolysis (Wiklund et al., 1996).

While changes in the WHC because of denaturalization of protein and ion concentration change have been reported (Wu \& Smith, 1987), these data showed venison in T1 (limit-fed concentrate supplement) exhibited approximately $2.83 \%$ greater WHC than T2 (ad libitum access to concentrate supplement) $(P$ $>0.05$ ). WHC is an important characteristic of meat quality because the loss of water affects the appearance of vacuum-packaged meat (Lee et al., 2005) and is related to the juiciness of the meat after it is cooked (Wiklund et al., 2003). Thus, these data demonstrate that reducing concentrate feed supplementation can produce soft and juicy venison.

Table 4 Treatment means for the physical properties and cholesterol content of venison from sika deer fed supplemental concentrate at $1.5 \%$ of live weight (T1) or ad libitum (T2)

\begin{tabular}{lcc}
\hline & \multicolumn{2}{c}{ Treatment } \\
\cline { 2 - 3 } Parameter & $\mathrm{T} 1(\mathrm{n}=3)$ & $\mathrm{T} 2(\mathrm{n}=3)$ \\
\hline Cooking loss (\%) & $32.12 \pm 0.87$ & $32.02 \pm 2.10$ \\
Shear force $(\mathrm{kg})$ & $8.09 \pm 1.25$ & $7.85 \pm 0.98$ \\
$\mathrm{pH}$ & $5.69 \pm 0.79$ & $5.59 \pm 0.68$ \\
Water holding capacity (\%) & $59.59 \pm 2.95^{\mathrm{a}}$ & $56.76 \pm 2.44^{\mathrm{b}}$ \\
Cholesterol (mg/100 g) & $31.82 \pm 2.10^{\mathrm{b}}$ & $35.03 \pm 2.92^{\mathrm{a}}$ \\
& \\
\hline a,b Values with different superscripts in the same row differ significantly $(P<0.05)$
\end{tabular}

Cholesterol concentration of meat is a major risk indicator for human beings, as higher concentrations of cholesterol can cause hypertension, arteriosclerosis, coronary thrombosis, and other diseases (Bergeron et al., 2019). However, sika deer venison has reduced cholesterol concentration relative to meats from other species, including elk, roe deer, and wild boar (Strazdina et al., 2012). Table 4 represents the response in carcass cholesterol concentration to the level of concentrate feed supplementation. The cholesterol concentration of venison from animals subjected to T2 was greater $(P>0.05)$ than for T1.

Consumption of red meat has decreased over the last few decades owing to concern about its association with increased heart disease (Bergeron et al., 2019). Red meat is rich in fats and cholesterol, and its consumption is associated with increased blood cholesterol levels (Bergeron et al., 2019). Subjects with hypercholesterolemia had greater levels of low-density lipoprotein and total cholesterol, which may contribute to coronary heart disease, such as acute ischaemic heart, and cerebral diseases manifested by unstable angina, acute thrombotic infarction, shock, and sudden death (Bergeron et al., 2019). A previous study reported cholesterol concentrations in the wild elk, deer, and roe deer meat to be $64.41 \mathrm{mg} / 100 \mathrm{~g}, 57$ $\mathrm{mg} / 100 \mathrm{~g}$, and $67.92 \mathrm{mg} / 100 \mathrm{~g}$, respectively (Strazdina et al., 2012). However, the sika deer in this study had a reduced cholesterol concentration $(31.82-35 \mathrm{mg} / 100 \mathrm{~g})$ compared with the deer that were studied by Strazdina et al. (2012).

\section{Conclusions}

The provision of concentrate supplement ad libitum lowers venison quality by reducing WHC\%, altering meat colour, and increasing total fat content and cholesterol concentration. These results provide fundamental data from which to develop feeding strategies for venison production, and assist venisonproducing farmers to develop optimal management strategies to increase production and improve profitability 
of domestic deer enterprises. Such efforts would contribute to the growth of the sika deer market, thereby improving the viability of deer farming and promoting wildlife conservation.

\section{Acknowledgments}

This work was supported by the Cooperative Research Program for Agriculture Science \& Technology Development (Project No. PJ01431501) and Fellowship Program of the National Institute of Animal Science, Rural Development Administration, Republic of Korea.

\section{Author's Contributions}

This study was jointly designed, conducted, and interpreted by all cited authors. All authors have read and approved the final manuscript.

\section{Conflict of Interest Declaration}

The authors declare no competing interests.

\section{References}

AOAC, 1995. Official methods of analysis. 16th edition. Association of Official Analytical Chemists, Inc., Arlington, Virginia, USA.

Bergeron, N., Chiu, S., Williams, P.T., King, S.M. \& Krauss, R.M., 2019. Effects of red meat, white meat, and nonmeat protein sources on atherogenic lipoprotein measures in the context of low compared with high saturated fat intake: A randomized controlled trial. Am. J. Clin. Nutr. Doi:10.1093/ajcn/nqz035.

Chae, H.S., Kim, N.Y., Cho, I.C., Cho, S.R., Cho, W.M., Park, Y.S., Oh, S.A., Jang, A., Seong, P.N. \& Ko, M.S., 2013. Effect of dietary supplementation of dried-citrus pulp and wheat bran on growth and meat quality in horses. J. Anim. Sci. Technol. 55, 219-227. Doi:10.5187/JAST.2013.55.3.219.

Cho, S.H., Kang, G.H., Seong, P.N., Park, B.Y., Jung, S.G., Kang, S.M., Kim, Y.C., Kim, J.H. \& Kim, D.H., 2011. Meat quality and nutritional properties of Hanwoo and imported New Zealand beef. Food Sci. Anim. Resour. 31, 935943. Doi:10.5851/kosfa.2011.31.6.935

Choi, S.H., Hwangbo, S., Kim S.W., Kim, Y.K., Sang, B.D., Myung, J.H., Hur, S.N. \& Jo, I.H., 2007. Effects of dietary energy level on growth and meat quality of Korean black goats. J. Anim. Sci. Technol. 49, 509-514. Doi:10.5187/JAST.2007.49.4.509.

Cornforth, D., 1994. Colour - its basis and importance. In: A.M. Pearson \& T.R. Dutson [eds). Quality attributes and their measurement in meat, poultry and fish products. Advances in meat research. Volume 9. Springer, Boston, MA, USA. Doi:10.1007/978-1-4615-2167-9_2

Dransfield, E., 2003. Consumer acceptance - meat quality aspects. In: Proceedings of the 11th International Meat Symposium on Consistency of Quality, 29-30 January 2003 Pretoria, South Africa. pp.146-159.

Drew, K.R., 1985. Meat production from farmed deer. In: P.F. Fennessy \& K.R., Drew (eds). Biology of deer production. The Royal Society of New Zealand Bulletin, Wellington. pp. 285-290.

Drew, K.R., Stevenson, J.M. \& Fennessy, P.F., 1991. Venison - a marketable product. In: Proceedings of a Deer Course for Veterinarians. Deer Branch of the New Zealand Veterinary Association, Wellington. pp: 31-35.

Flesch, J., Mulley, R. \& Asher, G., 2002. Development of a body condition scoring system for farmed fallow deer (Dama dama). In: Proceedings of 5th International Deer Biology Congress, pp. 20-26.

Goñi, M.V., Beriain, M.J., Indurain, G. \& Insausti, K., 2007. Predicting Longissimus dorsi texture characteristics in beef based on early post-mortem colour measurements. Meat Sci. 76, 38-45. Doi:10.1016/j.meatsci.2006.10.012

Hoffman, L.C. \& Wiklund, E., 2006. Game and venison - meat for the modern consumer. Meat Sci. 74, $197-208$. Doi:10.1016/j.meatsci.2006.04.005

Kadim, I.T., Mahgoub, O., Al-Ajmi, D.S., Al-Maqbaly, R.S., Al-Mugheiry, S.M. \& Bartolome, D.Y., 2004. The influence of season on quality characteristics of hot-boned beef $\mathrm{m}$. longissimus thoracis. Meat Sci. 66, 831-836. Doi:10.1016/j.meatsci.2003.08.001.

Kim, K.W., Park, H.S., Lee, S.S., Yeon, S.H., Cho, C.Y., Kim, S.W. \& Lee, J., 2017. Effects of different feeding regimes on deer meat (venison) quality following chilled storage condition. Korean J. Food Sci. Anim. Res. 37, 511-517. Doi: 10.5851/kosfa.2017.37.4.511

King, A.T., Paniangvait, P., Jones, A.D. \& German, J.B., 1998. Rapid method for quantification of cholesterol in turkey meat and product. J. Food Sci. 63, 382-386. Doi:10.1111/j.1365-2621.1998.tb15747.x.

Kudrnáčová, E., Bartoň, L., Bureš, D. \& Hoffman, L.C., 2018. Carcass and meat characteristics from farm-raised and wild fallow deer (Dama dama) and red deer (Cervus elaphus): A review. Meat Sci. 141, 9-27. Doi:10.1016/j.meatsci.2018.02.020.

Lee, J.I., Lee, J.D., Ha, Y.J., Jung, J.D., Lee, J.W., Lee, J.R., Kwack, S.C., Kim, D.H. \& Do, C.H., 2005. Effects of dietary silkworm droppings on quality characteristics of pork loin. Food Sci. Anim. Resour. 25, 175-188. Doi:10.5187/JAST.2004.46.6.1013.

Mazumder, M.A.R., Hossain, M.M. \& Akter, S., 1998. Effect of levels of concentrate supplement on live weight gain and carcass characteristics in sheep on restricted grazing. Asian-Australasis. J. Anim. Sci. 11, 17-20. Doi:10.5713/ajas.1998.17.

Ministry of Agriculture Food and Rural Affairs, 2015. Statistics of farmed deer and number of slaughtered deer in Korea. In: F. a. R. A. Ministry of Agriculture (ed.).

Ngapo T. M. \& Dransfield, E., 2006. British consumers preferred fatness levels in beef: Surveys from 1955,1982 and 
2002. Food Qual. Prefer. 17, 412-417. Doi:10.1016/j.foodqual.2005.05.006.

Page, J.K., Wulf, D.M. \& Schwotzer, T.R., 2001. A survey of beef muscle colour and pH. J. Anim. Sci. 79, $678-687$. Doi:10.2527/2001.793678x.

Piaskowska, N., Daszkiewicz, T., Kubiak, D. \& Janiszewski, P., 2015. The effect of gender on meat (Longissimus Lumborum muscle) quality characteristics in the fallow deer (Dama Dama L.). Italian J. Anim. Sci. $14,3845$. Doi:10.4081/ijas.2015.3845.

Ryoichi, S., Degychi, T. \& Nagata, Y., 1993. Effectiveness of the filter paper press method for determining the water holding capacity of meat. Fleischwirtsch. 73, 1399-1400.

Serrano, M.P., Maggiolino, A., Pateiro, M., Landete-Castillejos, T., Domínguez, R., García, A., Franco, D., Gallego, L., Palo, P.D. \& Lorenzo, J.M., 2019. Carcass Characteristics and Meat Quality of Deer. In: J. Lorenzo, P. Munekata, F. Barba \& F. Toldrá (eds). More than Beef, Pork and Chicken - The Production, Processing, and Quality Traits of Other Sources of Meat for Human Diet. Springer, Cham. Doi:10.1007/978-3-030-05484-7_9.

Shin, H.T., Hudson, R.J., Gao, X.H. \& Suttie, J.M., 2000. Nutritional requirements and management strategies for farmed deer-review. Asian-Australas. J. Anim. Sci. 13, 561-573. Doi:https://doi.org/10.5713/ajas.2000.561.

Strazdina, V., Jemeljanovs, A. \& Sterna, V., 2012. Fatty acids composition of elk, deer, roe deer and wild boar beat hunted in Latvia. Int. J. Anim. Vet. Sci. 6, 765-768. Doi:10.5281/zenodo.1071826.

Tuckwell, C., 2003. The deer farming handbook. Rural Industries Research and Development Corporation, Canberra, Australia.

Vergara, H., Gallego, L., Garcia, A. \& Landete-Castillejos, T., 2003. Conservation of Cervus elaphus meat in modified atmospheres. Meat Sci. 65, 779-783. Doi:10.1016/S0309-1740(02)00282-6.

Volpelli, L.A., Valusso, R., Morgante, M., Pittia, P. \& Piasentier, E., 2003. Meat quality in male fallow deer (Dama dama): Effects of age and supplementary feeding. Meat Sci. 65, 555-562. Doi:10.1016/S0309-1740(02)00248-6.

Webster, J.R., Corson, I.D., Littlejohn, R.P., Masters, B.M. \& Suttie, J.M., 2000. Effect of diet energy density and season on voluntary dry-matter and energy intake in male red deer. Anim. Sci. 70, 547-554. Doi:10.1017/S1357729800051894.

Wheeler, T.L., Shackelford, S.D. \& Koohmaraie, M., 2000. Variation in proteolysis, sarcomere length, collagen content, and tenderness among major pork muscles. J. Anim. Sci. 78, 958-965. Doi:10.2527/2000.784958x.

Wiklund, E., Andersson, A., Malmfors, G. \& Lundstrom, K., 1996. Muscle glycogen levels and blood metabolites in reindeer (Rangifer tarandus tarandus L.) after transport and lairage. Meat Sci. 42, 133-144.

Wiklund, E., Pickova, J., Sampels, S. \& Lundstrom, K., 2001. Fatty acid composition of M. longissimus lumborum, ultimate muscle $\mathrm{pH}$ values and carcass parameters in reindeer (Rangifer tarandus tarandus L.) grazed on natural pasture or fed a commercial feed mixture. Meat Sci. 58, 293-298. Doi:10.1016/S0309-1740(01)00030-4.

Wiklund, E., Manley, T.R., Littlejohn, R.P. \& Stevenson-Barry, J.M., 2003. Fatty acid composition and sensory quality of musculus longissimus and carcass parameters in red deer (Cervus elaphus) grazed on natural pasture or fed a commercial feed mixture. J. Sci. Food Agric. 83, 419-424. Doi:10.1002/jsfa.1384

Wu, F.Y. \& Smith, S.B., 1987. Ionic strength and myofibrillar protein solubilization. J. Anim. Sci. 165, $597-602$. Doi:10.2527/jas1987.652597x.

Zomborszky, G., Szentmihalyi, I., Sarudi, I., Horn, P. \& Szabo, C.S., 1996. Nutrient composition of muscles in deer and boar. J. Food Sci. 61, 625-635. Doi:10.1111/j.1365-2621.1996.tb13172.x. 